\title{
How Nitrogenase Shakes - Initial Information about P-Cluster and FeMo-cofactor Normal Modes from Nuclear Resonance Vibrational Spectroscopy (NRVS)
}

\author{
Yuming Xiao ${ }^{\dagger}$, Karl Fisher $^{\perp}$, Matt C. Smith ${ }^{\dagger}$, William E. Newton ${ }^{\perp,{ }^{*}}$, David A. Case ${ }^{\llbracket,{ }^{*}}$, Simon \\ J. George ${ }^{\ddagger}$, Hongxin Wang ${ }^{\dagger, \ddagger}$, Wolfgang Sturhahn ${ }^{\S}$, Ercan E. Alp ${ }^{\S}$, Jiyong Zhao ${ }^{\S}$, Yoshitaka \\ Yoda ${ }^{\ddagger}$, and Stephen P. Cramer ${ }^{\dagger, \ddagger},{ }^{*}$ \\ †Department of Applied Science, University of California, Davis, CA 95616 \\ ‡Physical Biosciences Division, Lawrence Berkeley National Laboratory, Berkeley, CA 94720 \\ ^Department of Biochemistry, Virginia Tech, Blacksburg, VA 24061 \\ IDepartment of Molecular Biology, The Scripps Research Institute, La Jolla, CA 92037 \\ $\S$ Advanced Photon Source, Argonne National Laboratory, Argonne, IL 60439 \\ ¥JASRI, SPring-8, 1-1-1 Kouto, Mikazuki-cho, Sayo-gun, Hyogo 679-5198, Japan
}

\begin{abstract}
Nitrogenase catalyzes a reaction critical for life, the reduction of $\mathrm{N}_{2}$ to $\mathrm{NH}_{3}$, yet we still know relatively little about its catalytic mechanism. We have used the synchrotron technique of ${ }^{57} \mathrm{Fe}$ nuclear resonance vibrational spectroscopy (NRVS) to study the dynamics of the Fe-S clusters in this enzyme. The catalytic site FeMo-cofactor exhibits a strong signal near $190 \mathrm{~cm}^{-1}$, where conventional Fe-S clusters have weak NRVS. This intensity is ascribed to cluster breathing modes whose frequency is raised by an interstitial atom. A variety of Fe-S stretching modes are also observed between 250 and $400 \mathrm{~cm}^{-1}$. This work is the first spectroscopic information about the vibrational modes of the intact nitrogenase FeMo-cofactor and P-cluster.
\end{abstract}

\author{
Keywords \\ nitrogenase; NRVS; synchrotron radiation; normal mode; Mössbauer
}

\section{Introduction}

Biological nitrogen fixation, involving reduction of dinitrogen to ammonia, is the key reaction in the nitrogen cycle and the ultimate source for most nitrogen in living systems [1] [2,3]. In Azotobacter vinelandii ( $A v)$ the Mo-dependent nitrogenase $\left(\mathrm{N}_{2}\right.$ ase) that accomplishes this reaction uses electrons from an $\mathrm{Fe}_{4} \mathrm{~S}_{4}$ cluster in the $\sim 63 \mathrm{kDa}$ Fe protein $(A v 2)$ in a MgATP-dependent reaction to reduce the $\sim 230 \mathrm{kDa} \alpha_{2} \beta_{2} \mathrm{MoFe}$ protein $(A v l)$. Within the latter, an $\mathrm{Fe}_{8} \mathrm{~S}_{7}$ 'P-cluster' supplies electrons to the active site $\mathrm{MoFe}_{7} \mathrm{~S}_{9}$ ' $\mathrm{FeMo-}$ cofactor', which is extractable into organic solvents as 'FeMoco' [4].

\footnotetext{
•Corresponding authors: spcramer@ucdavis.edu,wenewton@vt.edu, case@ scripps.edu. Supporting Information Available

Potential Energy Distribution (PED) of representative normal modes in NRVS from normal mode analysis for M-center in nitrogenase is summarized in Table S1. A PVDOS comparison between $\left[\mathrm{Fe}_{3} \mathrm{~S}_{4}\left(\mathrm{SCH}_{3}\right)_{3}\right]^{3-}$ and FeMo-co using DFT calculation is shown in

Fig.S1. This material is available free of charge via the Internet at http://pubs.acs.org.
} 
A recent structure for $A v 1$ at $1.16 \AA$ resolution [5] revealed electron density at the center of the trigonal prismatic cage of $\mathrm{Fe}$ atoms in the FeMo-cofactor, and hence an overall $\mathrm{MoFe}_{7} \mathrm{~S}_{9} \mathrm{X}$ core cluster composition. The electron density is consistent with a light $(\mathrm{C}, \mathrm{N}$, or $\mathrm{O})$ atom. Characterization of the interstitial atom is essential for understanding both the biosynthesis of the FeMo-cofactor and the mechanism of nitrogenase. Although ENDOR and ESEEM experiments have revealed several ${ }^{14} \mathrm{~N}$ signals that are weakly coupled to the FeMo-cofactor spin, none of these exchange when the enzyme is turned over under ${ }^{15} \mathrm{~N}_{2}$ [6]. Furthermore, when Azotobacter vinelandii $(A v)$ is grown on ${ }^{15} \mathrm{~N}$-urea, no ${ }^{15} \mathrm{~N}$ ENDOR signals are observed from the extracted FeMo-cofactor [7].

Numerous DFT calculations have been performed using $\mathrm{X}=\mathrm{C}, \mathrm{N}$, or $\mathrm{O}$, as well as with an empty central site [8-16]. These studies point towards $\mathrm{N}$ as the most likely interstitial atom (but do not exclude $\mathrm{C}$ or $\mathrm{O}$ ); in some models $\mathrm{X}$ is inert, whereas in others, it is a product of the reaction mechanism. Clearly, the nature of $X$ cannot be decided by theory alone, and new experimental approaches are required for the characterization of $\mathrm{N}_{2}$ ase and for determining the nature of atom $\mathrm{X}$.

We report here the first information about vibrational modes of the Fe-S clusters in $\mathrm{N}_{2}$ ase, using the technique of nuclear resonance vibrational spectroscopy (NRVS) [17]. In this experiment, a highly monochromatic x-ray beam is scanned through a nuclear (in this case ${ }^{57} \mathrm{Fe}$ ) resonance. On the wings of the familiar 'recoil-free' Mössbauer resonance are additional features that correspond to nuclear transitions combined with either excitation or de-excitation of vibrational modes. NRVS theory has been explained elsewhere [17]; key to the current study is that intensity of a normal mode is proportional to the fraction of kinetic energy derived from ${ }^{57} \mathrm{Fe}$. From NRVS data, one can obtain an ${ }^{57} \mathrm{Fe}$-specific partial vibrational density of states (PVDOS) that complements infrared and Raman spectra.

\section{Experimental}

\section{Cell growth and purification of nitrogenase proteins}

The $A v$ wild-type strain was grown in the absence of a fixed-nitrogen source in a 24-L fermenter at $30^{\circ} \mathrm{C}$ in a modified, liquid Burk medium [18]. All cultures contained $20 \mu \mathrm{M}{ }^{57} \mathrm{FeCl}_{3}$ and $10 \mu \mathrm{M} \mathrm{Na}_{2} \mathrm{MoO}_{4}$ and were grown to a final cell density of $250 \mathrm{Klett}$ units recorded on a Klett-Summerson meter equipped with a number 54 filter. All manipulations of $\mathrm{N}_{2}$ ase proteins were performed anaerobically using either a Schlenk line or an anaerobic glove box operating at less than $1 \mathrm{ppm} \mathrm{O}_{2}$. After harvesting, cell extracts were prepared by diluting the whole cells with an equal amount of $50 \mathrm{mM}$ Tris $\mathrm{pH} 8.0$ prior to passage through a French pressure cell and centrifugation at $98,000 \mathrm{~g}$ for $90 \mathrm{~min} . \mathrm{N}_{2}$ ase component proteins were separated by anaerobic Q-Sepharose anion-exchange column chromatography using a linear $\mathrm{NaCl}$ concentration gradient. $A v 2$ was purified to homogeneity by fractionation from a second Q-Sepharose column. $A v 2$ used in these experiments was obtained from a parallel growth that contained ${ }^{56} \mathrm{FeCl}_{3}$. $A v 1$ was further purified by Sephacryl S-200 gel filtration and phenyl-Sepharose hydrophobic-interaction chromatography [19]. The purified $\mathrm{N}_{2}$ ase proteins were concentrated individually using an Amicon microfiltration pressure concentrator before buffer exchange to $25 \mathrm{mM}$ HEPES pH7.5, $100 \mathrm{mM} \mathrm{NaCl}, 10 \mathrm{mM} \mathrm{MgCl}_{2}$ and $2 \mathrm{mM} \mathrm{Na}_{2} \mathrm{~S}_{2} \mathrm{O}_{4}$ by dialysis at $4^{\circ} \mathrm{C}$. Purified wildtype $A v 2$ and $A v 1$ had specific activities of 2500 and 2200 nmoles $^{\mathrm{H}_{2}}$ (min mg protein) ${ }^{-1}$ at $30^{\circ} \mathrm{C}$, respectively, when assayed in the presence of an optimal amount of the purified complementary component protein as described previously [19]. Protein concentrations were determined by the Lowry method.

The DJ1007 mutant $A v$ strain contains a deletion in the nifE gene and a polyhistidine tail located near the carboxy-terminus of the $\alpha$-subunit. DJ1007 cells were grown as described 
for the wild-type strain but in the presence of $10 \mathrm{mM}$ urea as a fixed-nitrogen source. When the cell density reached 250 Klett units, the culture was concentrated using a Pellicon cell concentrator (Millipore). The cells were resuspended in Burk medium with no added fixednitrogen source and allowed to derepress for 3.5 hours during which time nif-gene expression occurred. After harvesting, crude extracts were prepared by osmotic shock [20], followed by centrifugation at 98,000 $\mathrm{g}$ for $90 \mathrm{~min}$. The apo-MoFe protein $(\triangle n i f E: A v l)$ was purified using immobilized metal-affinity chromatography [21]; an additional Q-Sepharose column was utilized to remove a contaminating protein.

\section{Extraction of FeMoco from Av1}

$A v 1$ was purified as above through the gel-filtration step, yielding protein with a specific activity of $\sim 1000$ nmoles $\mathrm{H}_{2}$ (min mg protein) ${ }^{-1}$ and a Mo content of $\sim 1$ g-atom per mole $A v 1$. After dialysis to lower the $\mathrm{NaCl}$ concentration, the $A v l$ was loaded onto a DE-52 cellulose column that had been washed with $50 \mathrm{mM}$ Tris $\mathrm{pH} 7.4$ buffer containing $2 \mathrm{mM}$ $\mathrm{Na}_{2} \mathrm{~S}_{2} \mathrm{O}_{4}$. The bound protein was washed with $N, N$-dimethylformamide containing $50 \mathrm{mM}$ $2,2^{\prime}$-bipyridine, $5 \mathrm{mM}$ phosphate buffer $\mathrm{pH} 8,2 \mathrm{mM} \mathrm{Na}_{2} \mathrm{~S}_{2} \mathrm{O}_{4}$ and water $(c a .5 \% \mathrm{v} / \mathrm{v})$ until the non-cofactor iron was completely eluted. The column was then washed with $\mathrm{N}$ methylformamide (NMF) containing $5 \mathrm{mM}$ phosphate buffer $\mathrm{pH} 8,2 \mathrm{mM} \mathrm{Na}_{2} \mathrm{~S}_{2} \mathrm{O}_{4}$ and water $(c a .5 \% \mathrm{v} / \mathrm{v})$, and FeMoco was then eluted with NMF that contained 500mM tetraethyl ammonium chloride, $5 \mathrm{mM}$ phosphate buffer $\mathrm{pH} 8,2 \mathrm{mM} \mathrm{Na}_{2} \mathrm{~S}_{2} \mathrm{O}_{4}$ and water (ca. $5 \% \mathrm{v} / \mathrm{v}$ ). The eluted FeMoco was concentrated approximately 20 -fold by distilling off the NMF under vacuum at $40^{\circ} \mathrm{C}$. FeMoco was assayed [22] by reconstitution of the DJ42 Av strain, which has a deletion for the FeMo-cofactor biosynthetic genes nifENX. The FeMoco used in this study activated a DJ42 crude extract and reduced $65 \mathrm{nmol} \mathrm{C}_{2} \mathrm{H}_{2}$ (min mg protein) ${ }^{-1}$.

\section{Nuclear Resonance Vibrational Spectroscopy}

For NRVS measurements, samples were loaded into $3 \times 7 \times 1 \mathrm{~mm}^{3}$ Lucite cuvettes inside an anaerobic glove box and frozen. The tops of the cuvettes were sealed with thin Kapton tape to allow better escape of the internal conversion Fe K x-ray fluorescence. ${ }^{57} \mathrm{Fe}$ NRVS spectra were recorded using published procedures [17] at beamline 3-ID at the Advanced Photon Source (APS) [23] and beamline 9-XU at SPring-8 [24]. During the measurements, samples were maintained at low temperatures using liquid He. Spectra were recorded between $-20 \mathrm{meV}$ and $80 \mathrm{meV}$ in $0.25 \mathrm{meV}$ steps, using avalanche photodiode detectors [25]. Each scan took $\sim 40$ minutes. The monochromator energy scales were calibrated using the NRVS of $\left(\mathrm{NEt}_{4}\right)\left({ }^{57} \mathrm{FeCl}_{4}\right)$ [26].

\section{Normal Mode Calculations}

Spin-unrestricted density functional calculations were carried out using the Jaguar software [27], the PWPW91 exchange and correlation functional [28], and the lacvp* basis set, which combines 6-31G* functions for $\mathrm{H}, \mathrm{C}, \mathrm{N}$ and $\mathrm{O}$ with a double-zeta effective core potential for Fe. All calculations began from the geometry of the cofactor as found in the crystal structure. The homocitrate ligand to Mo was replaced with $\left(\mathrm{CH}_{3}\right)_{2} \mathrm{C}(\mathrm{O}) \mathrm{CO}_{2}{ }^{2-}$, the histidine with imidazole, and the cysteine ligand to $\mathrm{Fe}_{1}$ with $\mathrm{CH}_{3} \mathrm{~S}^{-}$; together with a central atom (X $=\mathrm{C}, \mathrm{N}, \mathrm{O}$ or nothing), this creates the "45-atom" model described earlier [11]. For $\mathrm{X}=\mathrm{C}, \mathrm{N}$, or $\mathrm{O}$, the formal oxidation states on the metal ions are $\mathrm{Mo}^{4+}+4 \mathrm{Fe}^{2+}+3 \mathrm{Fe}^{3+}$, consistent with Mössbauer and ENDOR assignments, and with our earlier calculated redox potentials (see the discussion in [11]). For $\mathrm{X}=\mathrm{C}$, we also investigated a model where one of the bridging sulfides at the "waist" of the cluster was protonated, so that the overall cluster charge was 3-, which we judged to be optimal in earlier redox potential calculations [11]. The model calculations with no central atom used formal metal oxidation states of $\mathrm{Mo}^{4+}+$ $6 \mathrm{Fe}^{2+}+1 \mathrm{Fe}^{3+}$, in order to have a total cluster charge as close as possible to the other models while maintaining an odd number of electrons. For $\mathrm{X}=\mathrm{N}$, the spin alignment we have 
labeled $b s 7[11,29]$ was found to be lowest in energy, with the $b s 6$ state next lowest, and we carried out vibrational calculations on both; for $\mathrm{X}=\mathrm{C}, \mathrm{O}$, or nothing, we used the $b s 7$ spin alignment. Further details of the calculations will be reported elsewhere. Vibrational densities of states were computed using a Gaussian broadening of $8 \mathrm{~cm}^{-1}$. The empirical normal mode calculations were carried out on FeMo-co models using a Urey-Bradley force field and a special modification of program 'Vibratz' to calculate the NRVS spectra [30].

\section{Results and Discussion}

Crystallographic models for the P-cluster and FeMo-cofactor are shown in Figure 1, and the ${ }^{57} \mathrm{Fe}$ PVDOS for ${ }^{57} \mathrm{Fe}$-enriched $A v 1$ is shown in Figure 2. This spectrum reflects the overlap of dozens of bands from both FeMo-cofactors and P-clusters; each of which could contribute more than 60 normal modes. To simplify the analysis, we recorded spectra for the $\triangle$ nifE mutant $A v 1$ that only contains P-clusters, as well as for isolated FeMoco (Figure 2). The $\Delta$ nifE mutant sample exhibits an extremely broad spectrum, presumably because the $\mathrm{P}$ clusters have 2 sets of coupled Fe atoms in 3 distinct environments. The strongest band $\left(130-160 \mathrm{~cm}^{-1}\right)$ can be assigned to S-Fe-S bending. The only other distinct feature (240$265 \mathrm{~cm}^{-1}$ ) in the P-cluster spectrum derives from Fe-S stretching motion. Assuming that the P-clusters change little between wild-type and $\Delta$ nifE Avl proteins, an Avl minus $\Delta$ nifE Avl difference spectrum should reflect just the FeMo-co ${ }^{57} \mathrm{Fe}$ density of states.

The Av1 minus $\triangle$ nifE Avl difference spectrum PVDOS (Figure 2) is dominated by a peak near $188 \mathrm{~cm}^{-1}$ with a resolved shoulder at $172 \mathrm{~cm}^{-1}$ — where there is much less intensity in the $\Delta$ nifE spectrum. The same pair of features is seen in the isolated FeMoco spectrum, which also has a higher energy band at $208 \mathrm{~cm}^{-1}$ (Figure 2). In both the isolated FeMo-co and difference spectra, there are S-Fe-S bend modes around $140 \mathrm{~cm}^{-1}$, as well as strong bands related to Fe-S stretching motion $\sim 270$ and $\sim 320 \mathrm{~cm}^{-1}$, with additional modes seen out to $>400 \mathrm{~cm}^{-1}$. On the low energy side, below $\sim 100 \mathrm{~cm}^{-1}$, there are features corresponding to cluster torsional modes and larger scale motion of the protein skeleton.

What does the PVDOS tell us about the $\mathrm{N}_{2}$ ase FeMo-cofactor and isolated FeMoco? Empirically, the most striking difference with Fe-S cluster model compounds is the set of strong bands around $190 \mathrm{~cm}^{-1}$. By comparison, a 4Fe model cluster has low NRVS intensity in this region (Figure 2) [31]. Modes related to Fe-S-Fe bending motion are between 130 and $160 \mathrm{~cm}^{-1}$ in $\mathrm{Fe}_{4} \mathrm{~S}_{4}$ clusters [31]. NRVS bands are also observed from 130 to $160 \mathrm{~cm}^{-1}$ for the protein-bound FeMo-cofactor and isolated FeMoco, but at lower intensity than the $180-190 \mathrm{~cm}^{-1}$ features. In di-ferric $\mathrm{Fe}_{2} \mathrm{~S}_{2}$ clusters, $\mathrm{Fe}-\mathrm{S}$-Fe bending modes are at $140-180$ $\mathrm{cm}^{-1}$ (Figure 2) [26]. NRVS spectra are not yet available for $\mathrm{Fe}_{3} \mathrm{~S}_{4}$ clusters, but DFT calculations suggest that their strongest bending modes will also peak around $150 \mathrm{~cm}^{-1}$ (Supplementary Material). Furthermore, in the models, the strongest PVDOS features are in the Fe-S stretching region above $\sim 250 \mathrm{~cm}^{-1}$. In summary, the $190 \mathrm{~cm}^{-1}$ peak is unusual both in its position and in its relative NRVS intensity.

One Fe cluster that does have significant intensity in modes near $190 \mathrm{~cm}^{-1}$ is $\left[\mathrm{Fe}_{6} \mathrm{~N}(\mathrm{CO})_{15}\right]^{3-}$ (Figure 2). This quasi-octahedral CO-bridged complex has limitations as a model for the trigonal prismatic FeMo-cofactor cluster; nevertheless, it appears relevant that the strongest peak in its spectrum is a breathing mode for the $\mathrm{Fe}_{6}$ octahedron at $195 \mathrm{~cm}^{-1}$. By comparison, breathing modes for $\left[\mathrm{Fe}_{4} \mathrm{~S}_{4}(\mathrm{SR})_{4}\right]^{2-}$ cubane models occur near $145 \mathrm{~cm}^{-1}$ [31]. We attribute the higher frequency in $\left[\mathrm{Fe}_{6} \mathrm{~N}(\mathrm{CO})_{15}\right]^{3-}$ and the FeMo-cofactor/FeMoco in part to the extra rigidity conferred by bonding to an interstitial atom.

One approach to interpretation of vibrational spectra is the use of empirical potentials. In the past, Urey-Bradley force fields (UBFF) have successfully been applied to mononuclear $\mathrm{Fe}$ 
sites in rubredoxins [32], 2Fe [33,34] and 4Fe ferredoxins and model complexes [35], and more recently, $\mathrm{MoFe}_{3} \mathrm{~S}_{4}$ clusters [36,37]. For our analysis, we built (in silico) a 23-atom model with $\mathrm{C}_{3 \mathrm{v}}$ symmetry. The Mo end of the cluster was terminated with 3 oxygens, whereas an S-C ligand was used at the Fe end (Figure 5). We then optimized the UBFF parameters so that the $16 \mathrm{~A}_{1}, 5 \mathrm{~A}_{2}$, and 21 doubly-degenerate $\mathrm{E}$ normal modes best simulated the experimental Avl - $\triangle$ nifE:Avl PVDOS.

What structural features and parameters give rise to the unusual FeMo-cofactor spectrum? As summarized in Table 1, the Fe-S force constants that we arrived at are similar to or lower than those used by other groups to model $\mathrm{Fe}_{4} \mathrm{~S}_{4}$ clusters $[35,36]$, and the $\mathrm{Fe}-\mathrm{Fe}$ interaction constant is also not unusual -0.27 mdyne/ $\AA$ compared to 0.19 [35] or $0.22-0.36$ mdyne $/ \AA$ [37]. By themselves, none of the parameters would drastically alter the spectrum. One special feature of the model is of course the 'interstitial' atom. Assuming a central N, the UBFF simulations are optimized with Fe-N stretching force constants of $\sim 0.3$ mdyne/Å. With this force field, several strong Fe breathing modes appear between 170 and $210 \mathrm{~cm}^{-1}$ (Figure 5). Because the central atom contributes little to the kinetic energy of these low frequency modes, similar conclusions would be reached with the same force constants for interstitial $\mathrm{C}$ or $\mathrm{O}$.

As noted by Lee and Holm [38,39], there are no really good models for $\mathrm{N}$ bound to weakfield Fe in an FeMo-cofactor-like geometry. (However, there has been some recent progress in this area [40]). In $\mu$-nitrido bridged low-spin Fe(III) porphyrin dimers, Fe-N force constants as high as 4.5 mdyne/ $\AA$ have been reported [41], compared to a 2.2 mdyne/ $\AA$ value reported for hexacoordinate $\mathrm{N}$ in $\left[\mathrm{Fe}_{6} \mathrm{~N}(\mathrm{CO})_{15}\right]^{3-}[42]$. Assuming a Fe-N distance of $\sim 2.05 \AA$, a Badger's rule calculation for $\mathrm{K}(\mathrm{Fe}-\mathrm{N})$ yields $\sim 0.49$ mdyne/ $\AA$. Thus, the $\sim 0.3$ mdyne/Å value derived from the simulations indicates a rather weak interaction between the interstitial atom and its neighboring Fe atoms.

Another approach to interpretation of NRVS spectra is first principles calculation of the normal modes using density functional theory (DFT). A set of such calculations for $\mathrm{X}^{-} \mathrm{O}^{2-}$, $\mathrm{N}^{3-}$, or $\mathrm{C}^{4-}$ is shown in Figure 3. (Of course, in these calculations the final charge on the interstitial atom is much less negative than the formal oxidation state.) For $\mathrm{X}=\mathrm{O}^{2-}$, the strongest peak in the calculated PVDOS is at $\sim 152 \mathrm{~cm}^{-1}$; the maximum shifts to $174 \mathrm{~cm}^{-1}$ for $\mathrm{X}=\mathrm{N}^{3-}$, and to $181 \mathrm{~cm}^{-1}$ for $\mathrm{X}=\mathrm{C}^{4-}$. Taking the interstitial atom out yields a main peak below $150 \mathrm{~cm}^{-1}$ and a flatter intensity distribution between 200 and $500 \mathrm{~cm}^{-1}$.

Although the interstitial C model gives the closest match to the observed PVDOS, it also confers a relatively large negative charge on the cluster. We thus performed a final calculation allowing for protonation of the FeMo-cofactor. This ' $\mathrm{X}=\mathrm{C}^{4-}, \mathrm{H}^{+}$' model also gave a good simulation of the experimental PVDOS, with a primary peak at $184 \mathrm{~cm}^{-1}$, and generally higher frequencies for most modes (Figure 3 and Figure 4). At the current level of uncertainty between experiment and calculation, none of these models can be absolutely excluded.

Another aid to interpretation of the DFT results is to compare the PVDOS for different atoms within the $\mathrm{M}$ center, as we have done for Fe and the interstitial $\mathrm{X}$ in Figure 3 and for $\mathrm{Mo}, \mathrm{Fe}, \mathrm{S}$, and interstitial $\mathrm{C}$ in Figure 4. We have also illustrated the relative motions for two key predicted modes of the ' $\mathrm{X}=\mathrm{C}^{4-}, \mathrm{H}^{+}$' model in Figure 5. As expected, the breathing modes with strong NRVS intensity have little interstitial atom motion, and hence are very insensitive to light atom isotopic substitution. In contrast, we see that the interstitial has the greatest amount of motion in modes ranging from $350-420 \mathrm{~cm}^{-1}\left(\mathrm{X}=\mathrm{O}^{2-}\right)$ through $430-500$ $\mathrm{cm}^{-1}\left(\mathrm{X}=\mathrm{N}^{3-}\right)$ to $480-590 \mathrm{~cm}^{-1}\left(\mathrm{X}=\mathrm{C}^{4-}\right)$. These modes are all quite sensitive to the mass of the light atom. The Fe-S stretch modes between 220 and $420 \mathrm{~cm}^{-1}$ involve substantial S 
motion, and hence will exhibit measurable ${ }^{32} \mathrm{~S} /{ }^{36} \mathrm{~S}$ isotope shifts. With both DFT and UBFF, the atomic motions for the strongest NRVS modes can be described as breathing and/or bending of the central $\mathrm{Fe}$ cage. Some of the frequency differences arise from changes in the stiffness of these motions depending on the presence and nature of the interstitial atom.

The interstitial $X$ 'shake' modes, shown in Figure 5, have been discussed extensively in the context of $\left[\mathrm{M}_{6}(\mathrm{CO})_{\mathrm{X}}\right]^{\mathrm{n}-}$ clusters $[42,43]$, but they have yet to be observed for $\mathrm{N}_{2}$ ase or FeMo-co. In the DFT calculations, the 'shake' modes for the FeMo-cofactor with $\mathrm{X}=\mathrm{N}$ $\left(430-500 \mathrm{~cm}^{-1}\right)$ or $\mathrm{C}\left(480-590 \mathrm{~cm}^{-1}\right)$ are predicted to have much lower frequencies than the corresponding modes that are actually observed centered around $765 \mathrm{~cm}^{-1}$ or $790 \mathrm{~cm}^{-1}$ in $\left[\mathrm{Fe}_{6} \mathrm{~N}(\mathrm{CO})_{15}\right]^{3-}$ or $\left[\mathrm{Fe}_{6} \mathrm{C}(\mathrm{CO})_{16}\right]^{2-}$ respectively [42-44]; this is consistent with a larger cavity in the FeMo-cofactor (e.g. mean Fe-X distance of $2.00 \AA$ ㄴ vs. $1.86 \AA$ in $\left[\mathrm{Fe}_{6} \mathrm{~N}(\mathrm{CO})_{15}\right]^{3-}$ ). Since they primarily involve oscillation of $\mathrm{X}$, either along or perpendicular to the cluster approximate symmetry axes, there is little Fe motion in the 'shake' modes and hence a very small predicted NRVS signal. With approximate ungerade symmetry, they are also very weak in Raman spectroscopy. However, the motion of the charged interstitial gives rise to a large transition dipole, and these modes have strong infrared signals and large light atom isotope shifts. Attempts to exploit these predictions are of course underway.

In summary, the vibrational spectra derived from NRVS experiments support the presence of an interstitial atom in both isolated FeMoco and in the Avl-bound FeMo-cofactor. Future experiments by NRVS and other vibrational spectroscopies over a wider range of frequencies should help identify the chemical nature of the interstitial atom and help elucidate changes that occur during the catalytic mechanism of this enzyme.

\section{Supplementary Material}

Refer to Web version on PubMed Central for supplementary material.

\section{Acknowledgments}

This work was funded by NIH grants GM-44380 (SPC), GM-65440 (SPC), GM-39914 (DAC), and DK-37255 (WEN) and the DOE Office of Biological and Environmental Research (SPC). Use of the Advanced Photon Source is supported by the U.S. Department of Energy, Basic Energy Sciences; Office of Science, under Contract No. W-31-1-9-Eng-38.

\section{References and Notes}

1. Igarashi RY, Seefeldt LC. Crit. Rev. Biochem. Mol. Biol. 2003; 38:351-384. [PubMed: 14551236]

2. Rees DC, Tezcan FA, Haynes CA, Walton MY, Andrade S, Einsle O, Howard JB. Phil. Trans. R. Soc. A. 2005; 363:971-984. [PubMed: 15901546]

3. Dos Santos PC, Igarashi RY, Lee H-I, Hoffman BM, Seefeldt LC, Dean DR. Acc. Chem. Res. 2005; 38:208-214. [PubMed: 15766240]

4. Pickett CJ, Vincent KA, Ibrahim SK, Gormal CA, Smith BE, Best SP. Chemistry. 2003; 9:76-87. [PubMed: 12506366]

5. Einsle O, Tezcan FA, Andrade SLA, Schmid B, Yoshida M, Howard JB, Rees DC. Science. 2002; 297:1696-1700. [PubMed: 12215645]

6. Lee H-I, Benton PMC, Laryukhin M, Igarashi RY, Dean DR, Seefeldt LC, Hoffman BM. J. Am. Chem. Soc. 2003; 125:5604-5605. [PubMed: 12733878]

7. Yang T-C, Maeser NK, Laryukhin M, Lee H-I, Dean DR, Seefeldt LC, Hoffman BM. J. Am. Chem. Soc. 2005; 127:12804-12805. [PubMed: 16159266]

8. Dance I. Chem. Comm. 2003:324-325. [PubMed: 12613594]

9. Hinnemann B, Nørskov JK. J. Am. Chem. Soc. 2003; 125:1466-1467. [PubMed: 12568592] 
10. Schimpl J, Petrilli HM, Blochl PE. J. Am. Chem. Soc. 2003; 125:15772-15778. [PubMed: 14677967]

11. Lovell T, Liu T, Case DA, Noodleman L. J. Am. Chem. Soc. 2003; 125:8377-8383. [PubMed: 12837110]

12. Huniar U, Ahlrichs R, Coucouvanis D. J. Am. Chem. Soc. 2004; 126:2588-2601. [PubMed: 14982469]

13. Hinnemann B, Nørskov JK. J. Am. Chem. Soc. 2004; 126:3920-3927. [PubMed: 15038746]

14. Dance I. J. Am. Chem. Soc. 2004; 126:11852-11863. [PubMed: 15382920]

15. Dance I. J. Am. Chem. Soc. 2005; 127:10925-10942. [PubMed: 16076199]

16. Kastner J, Blochl PE. ChemPhysChem. 2005; 6:1724-1726. [PubMed: 16013077]

17. Sturhahn W. J. Phys. Cond. Matt. 2004; 16:S497-S530.

18. Strandberg GW, Wilson PW. Can. J. Microbiol. 1968; 14:25-31. [PubMed: 5644401]

19. Kim C-H, Newton WE, Dean DR. Biochem. 1995; 34:2798-2808. [PubMed: 7893691]

20. Shah VK, Davis LC, J BW. Biochim. Biophys. Acta. 1972; 256:498-511. [PubMed: 5016550]

21. Christiansen J, Goodwin PJ, Lanzillota WN, Seefeldt LC, Dean DR. Biochem. 1998; 37:1261112623. [PubMed: 9730834]

22. Paustian TD, Shah VK, Roberts GP. Biochem. 1990; 29:3515-3522. [PubMed: 2162195]

23. Toellner T. Hyp. Int. 2000; 125:3-28.

24. Yoda Y, Yabashi M, Izumi K, Zhang XW, Kishimoto S, Kitao S, Seto M, Mitsui T, Harami T, Imai Y, Kikuta S. Nucl. Inst. Meth. A. 2001; 467:715-718.

25. Kishimoto S, Yoda Y, Seto M, Kitao S, Kobayashi Y, Haruki R, Harami T. Nucl. Inst. Meth. A. 2004; 513:193-196.

26. Smith MC, Xiao Y, Wang H, George SJ, Coucovanis D, Koutmos M, Sturhahn W, Alp EE, Zhao J, Cramer SP. Inorg. Chem. 2005; 44:5562-5570. [PubMed: 16060605]

27. Jaguar. version 6.0. New York: Schrodinger, LLC; 2005.

28. Perdew JP, Chevary JA, Vosko SH, Jackson KA, Pedersen MR, Singh DJ, Fiolhais C. Phys. Rev. B. 1991; 46:6671-6687.

29. Lovell T, Li J, Liu T, Case DA, Noodleman L. J. Am. Chem. Soc. 2001; 123:12392-12410. [PubMed: 11734043]

30. Dowty E. Phys. Chem. Minerals. 1987; 14:67-79.

31. Xiao Y, Koutmos M, Case DA, Coucouvanis D, Wang H, Cramer SP. J. Chem. Soc. Dalton. 2006 accepted.

32. Czernuszewicz RS, Kilpatrick LK, Koch SA, Spiro TG. J. Am. Chem. Soc. 1994; 116:1134-1141.

33. Han S, Czernuszewicz RS, Kimura T, Adams MWW, Spiro TG. J. Am. Chem. Soc. 1989; 111:3505-3511.

34. Mitou G, Higgins C, Wittung-Stafshede P, Conover RC, Smith AD, Johnson MK, Gaillard J, Stubna A, Münck E, Meyer J. Biochem. 2003; 42:1354-1364. [PubMed: 12564939]

35. Czernuszewicz RS, Macor KA, Johnson MK, Gewirth A, Spiro TG. J. Am. Chem. Soc. 1987; 109:7178-7187.

36. Kern A, Nather C, Studt F, Tuczek F. Inorg. Chem. 2004; 43:5003-5010. [PubMed: 15285677]

37. Kern A, Näther C, Tuczek F. Inorg. Chem. 2004; 43:5011-5020. [PubMed: 15285678]

38. Lee SC, Holm RH. Proc. Nat. Acad. Sci. 2003; 100:3595-3600. [PubMed: 12642670]

39. Lee SC, Holm RH. Chem Rev. 2004; 104:1135-1158. [PubMed: 14871151]

40. Bennett MV, Stoian S, Bominaar EL, Münck E, Holm RH. J. Am. Chem. Soc. 2005; 127:1237812386. [PubMed: 16131219]

41. Crisanti MA, Spiro TG, English DR, Hendrickson DN, Suslick KS. Inorg. Chem. 1984; 23:38973901.

42. Della Pergola R, Bandini C, Demartin F, Diana E, Garlaschelli L, Stanghellini PL, Zanello P. J. Chem. Soc. Dalton Trans. 1996:747-754.

43. Creighton JA, Dellapergola R, Heaton BT, Martinengo S, Strona L, Willis DA. J. Chem. Soc. Chem. Commun. 1982:864-865. 
44. Stanghellini PL, Rossetti R. Comments Inorg. Chem. 1990; 9:263-303. 

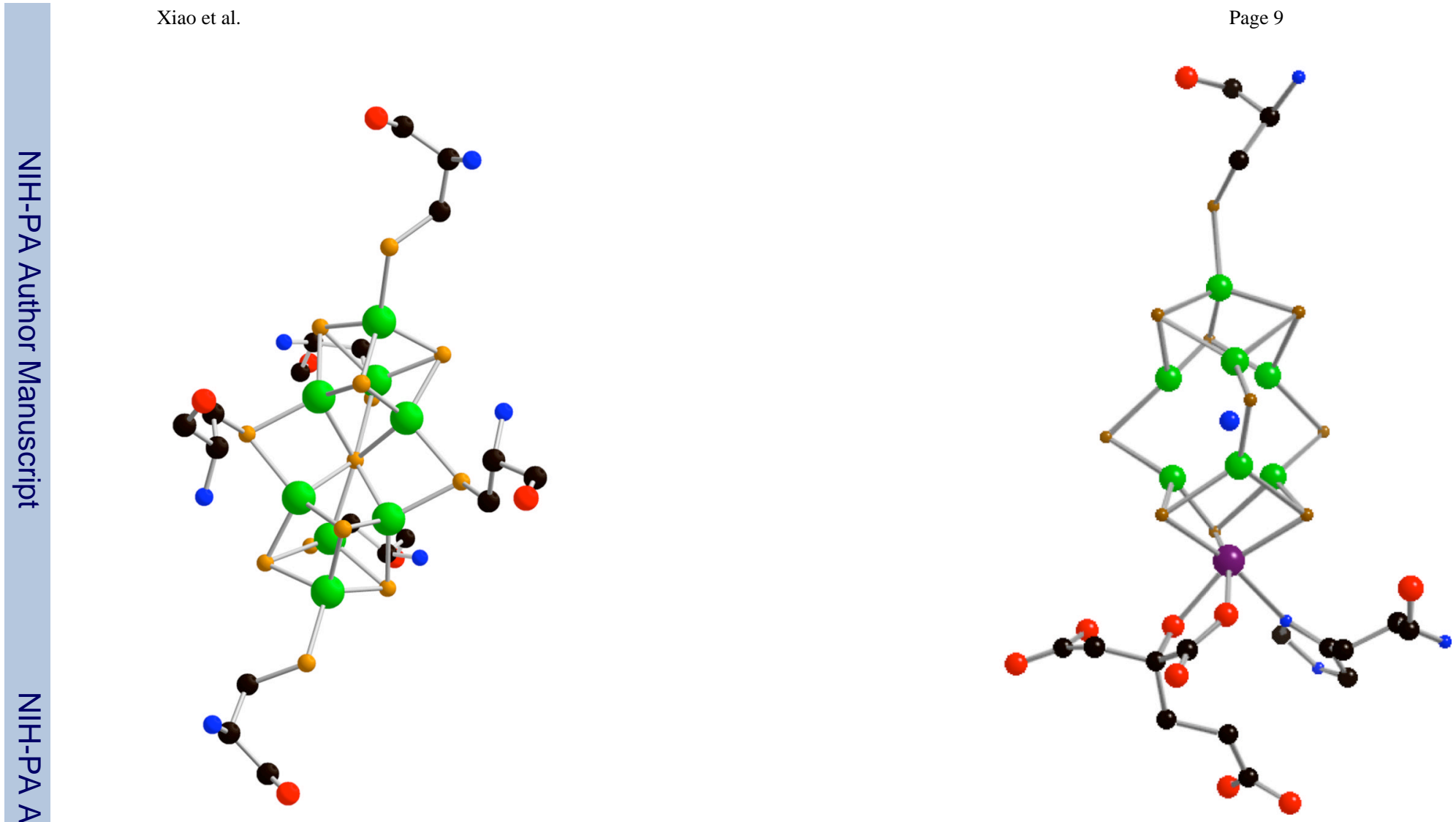

Figure 1.

Crystal structure models for (left) P-cluster and (right) FeMo-cofactor. 


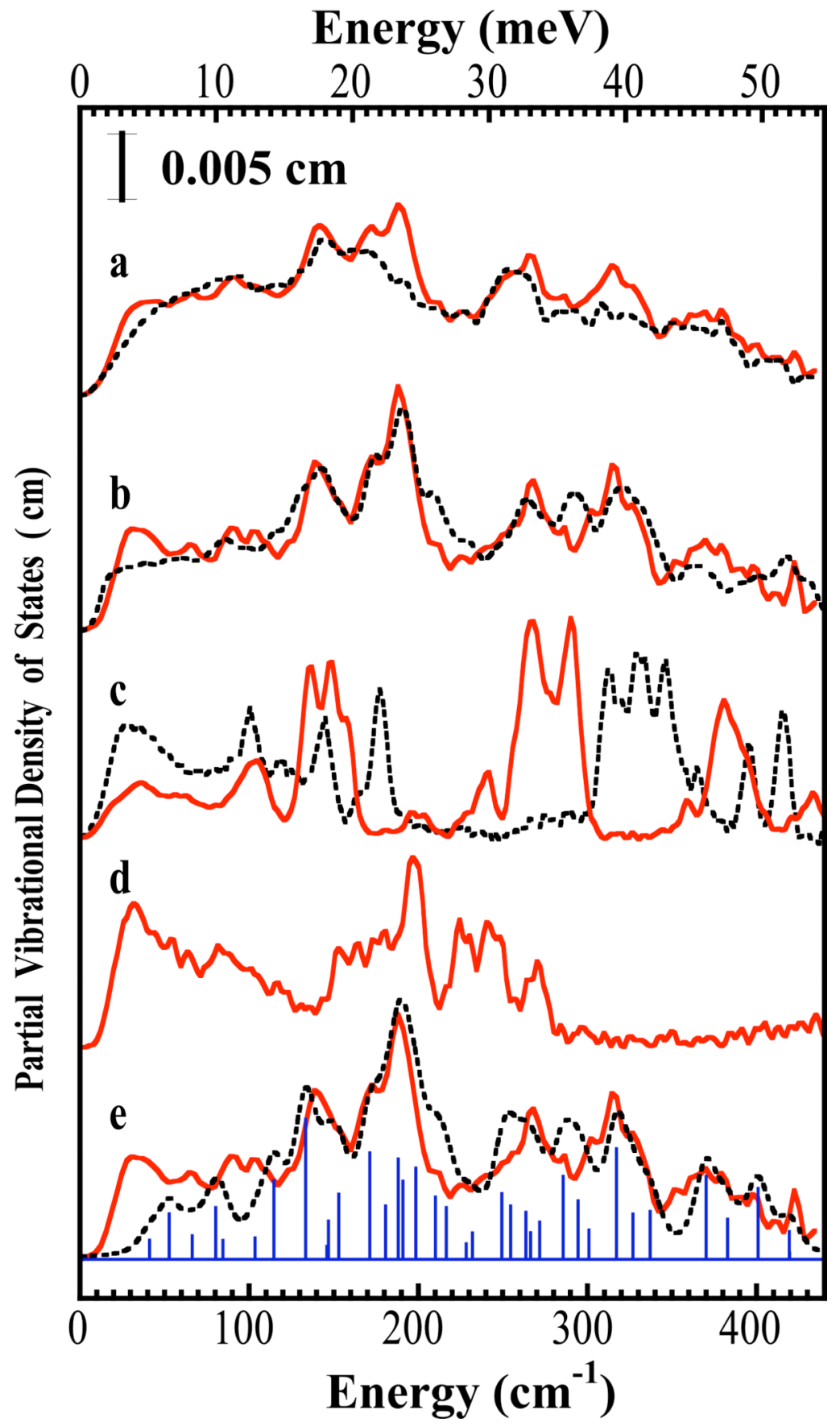

Figure 2.

experimental ${ }^{57} \mathrm{Fe}$ PVDOS functions, $D_{F e}(\vec{v})$, for (top to bottom) (a) Avl (__ vs. $\Delta$ nifE $A v 1$ (- -); (b) Av1- $\Delta$ nifE:Av1 difference spectrum (_-_) vs. isolated FeMoco (- -); (c)

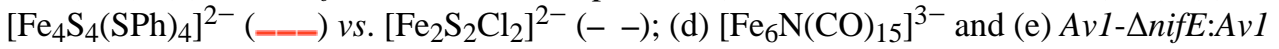
(_) vs. Urey-Bradley simulation (- -) (sticks represent amplitude of modes before broadening). 


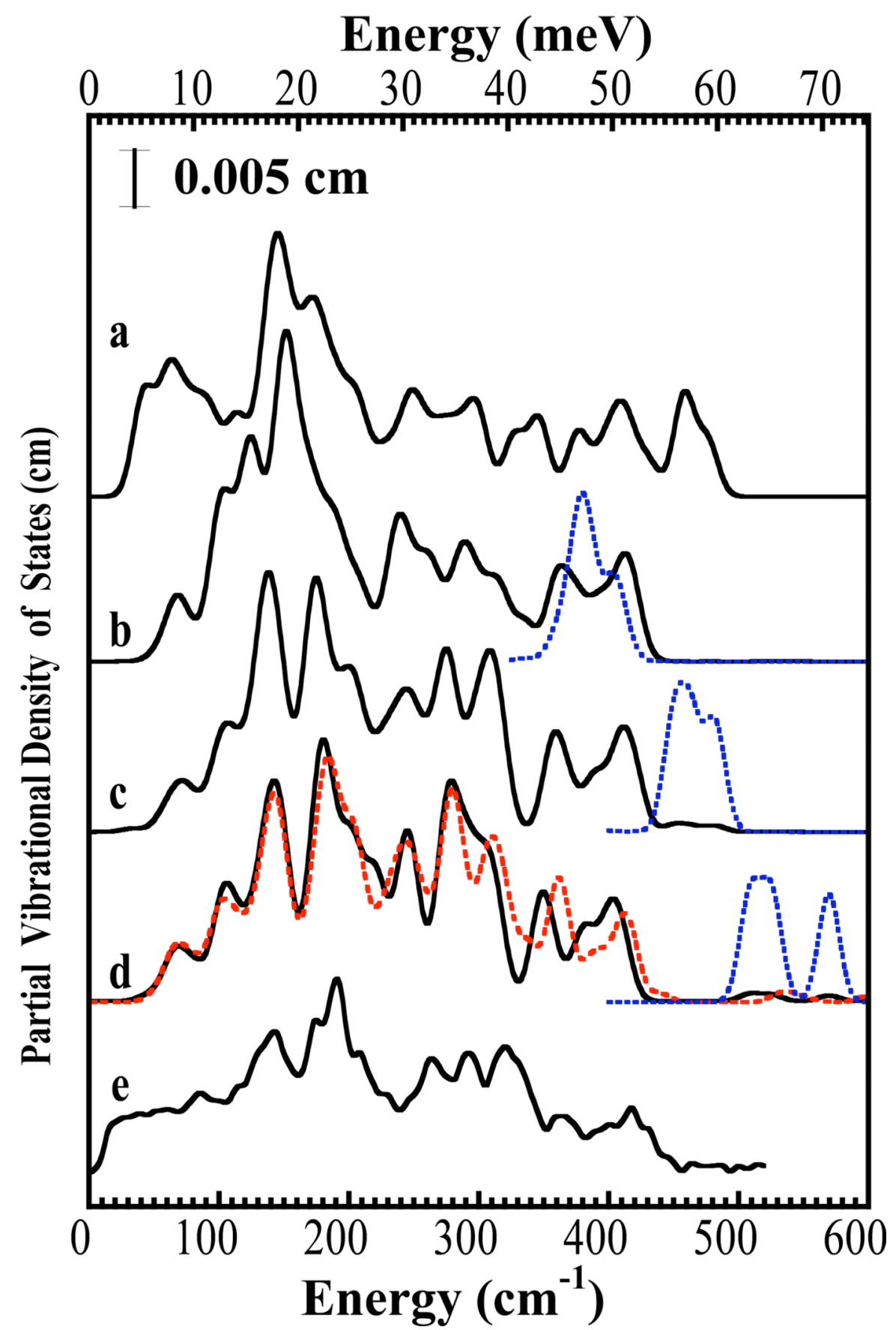

Figure 3.

DFT-calculated ${ }^{57} \mathrm{Fe}(----)$ and light atom (oovo0000) PVDOS for (top to bottom) (a) empty site; (b) ' $\mathrm{X}=\mathrm{O}^{2-}$; (c) ' $\mathrm{X}=\mathrm{N}^{3-}$; (d) ' $\mathrm{X}=\mathrm{C}^{4-,}$ vs. ' $\mathrm{X}=\mathrm{C}^{4-}, \mathrm{H}^{+}$' (_- ) (light atom not shown); (e) isolated FeMoco spectrum. 


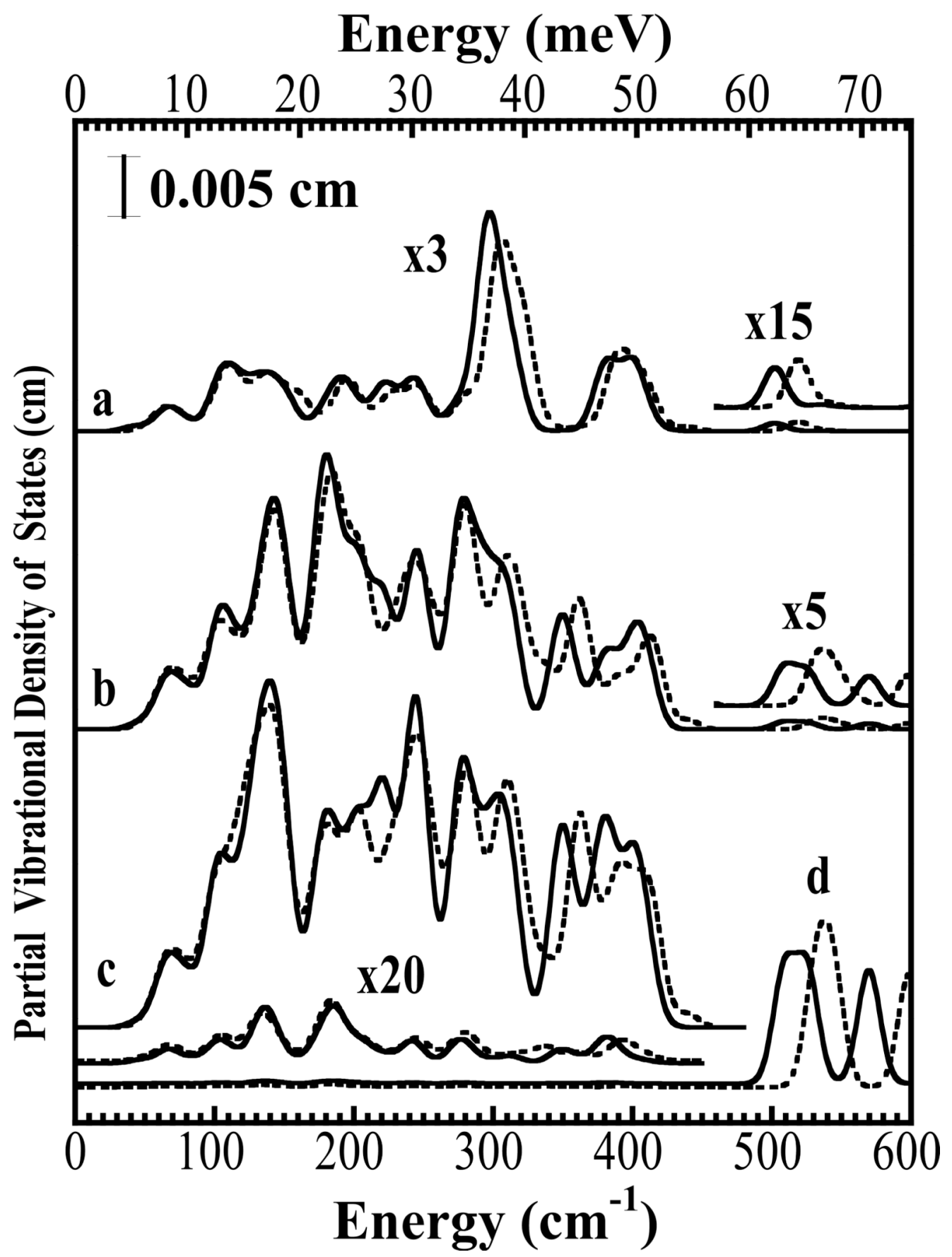

Figure 4.

Decomposition of ' $\mathrm{X}=\mathrm{C}^{4-}$ ' $\mathrm{DFT}(----)$ and ' $\mathrm{X}=\mathrm{C}^{4-}, \mathrm{H}^{+}$' $\mathrm{DFT}\left(--\right.$ - $^{-}$into (top to bottom) (a) Mo, (b) Fe, (c) S, and (d) C PVDOS. 


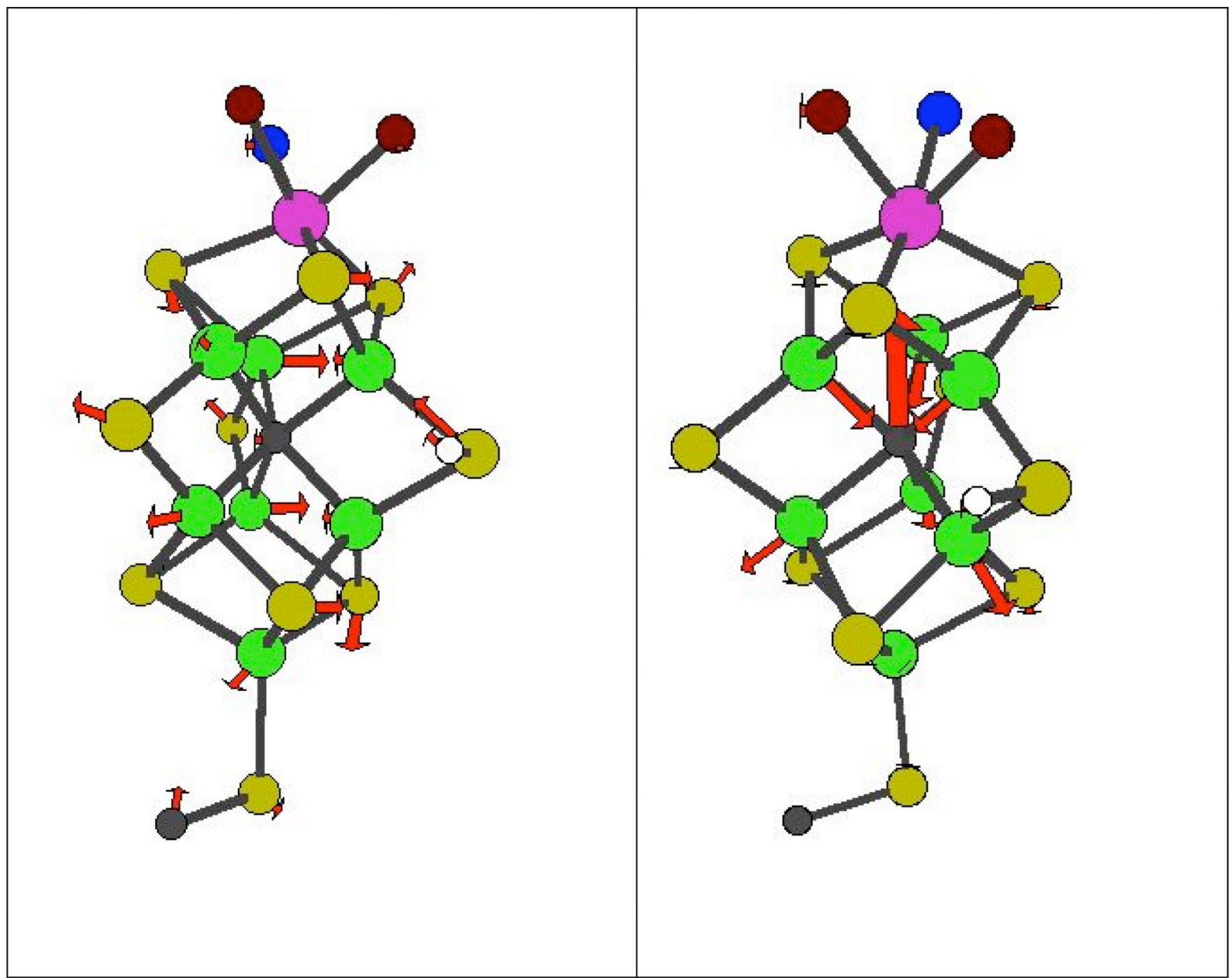

Figure 5.

Simplified FeMo-cofactor model with arrows indicating relative atomic motion in calculated from DFT theory for (left) a breathing mode at $177 \mathrm{~cm}^{-1}$ and (right) a 'shake' mode at 599 $\mathrm{cm}^{-1}$. Color scheme is $\mathrm{Fe}$ green, Mo purple, $\mathrm{S}$ orange, $\mathrm{C}$ black, $\mathrm{N}$ blue and $\mathrm{O}$ red. 


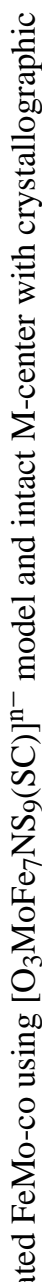

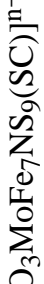

은

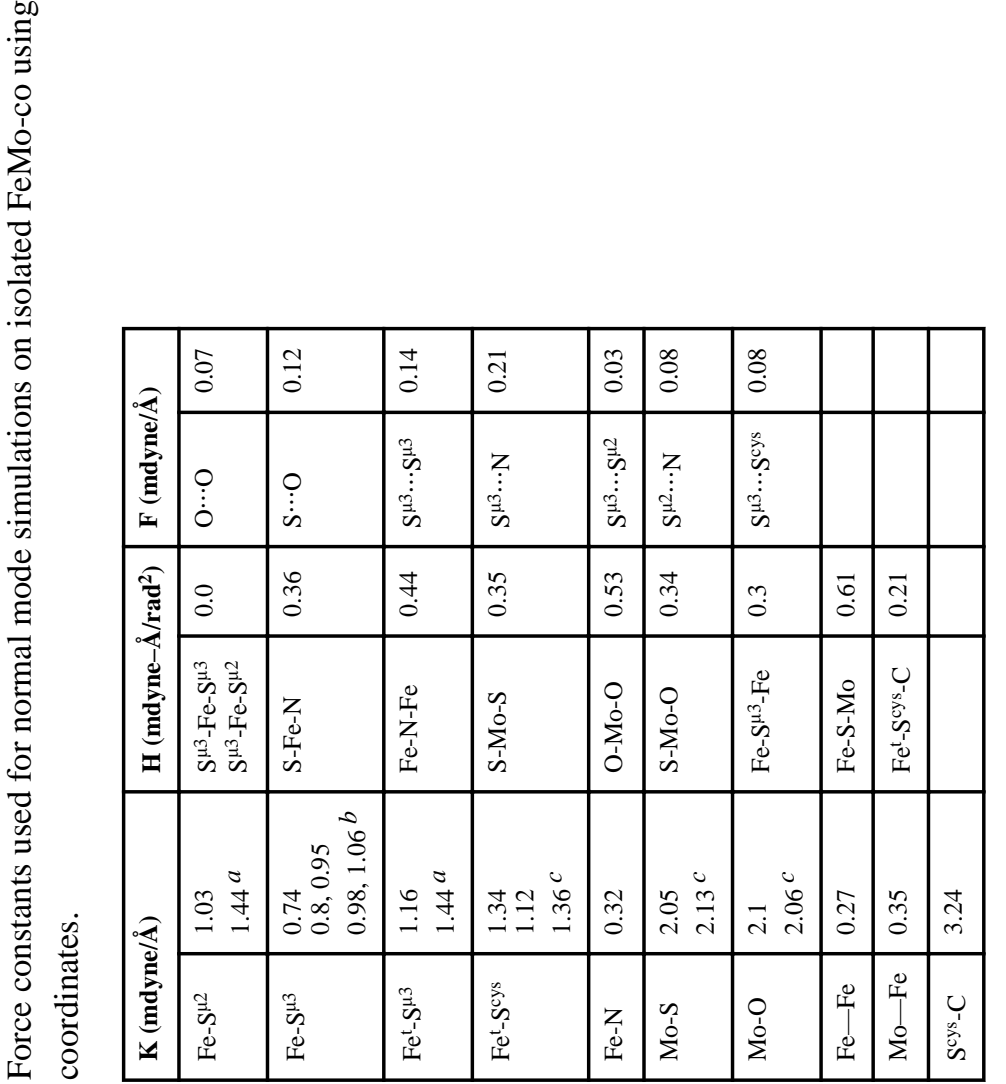

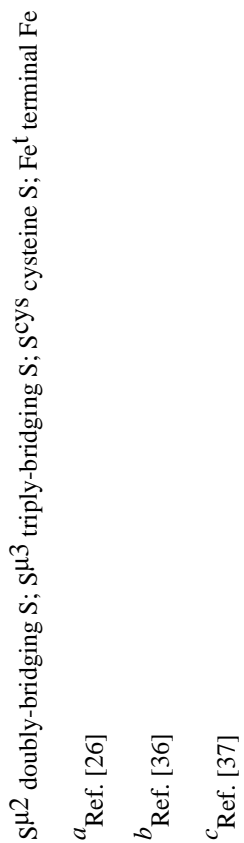

$J$ Am Chem Soc. Author manuscript; available in PMC 2011 September 16. 